\title{
Sistema de Gerenciamento e Controle Interno: uma Análise dos Escritórios de Contabilidade de Belo Horizonte/MG e Região Metropolitana a partir da Taxonomia de Kaplan e Cooper
}

\section{System Management and Internal Control: an Analysis of the Accounting Firms in Belo Horizonte / MG and the Metropolitan Area from the Taxonomy of Kaplan and Cooper}

${ }^{a}$ Wendel Alex Castro Silva; ${ }^{b}$ Adriana Maria Rocha; ${ }^{c}$ Alfredo Alves Oliveira Melo

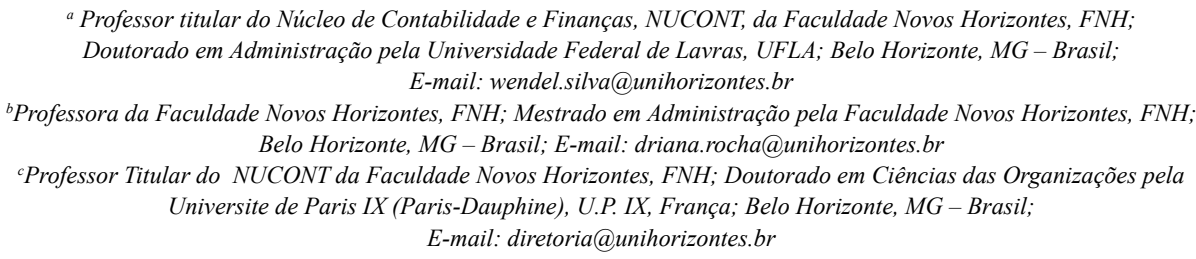

\section{Resumo}

O objetivo deste estudo foi analisar o nível de gerenciamento e controle interno dos escritórios de contabilidade a partir da tipologia de quatro estágios desenvolvida por Kaplan e de Cooper (1998) para projetar sistemas gerenciais. Na metodologia, adotou-se o estudo descritivo, por meio de pesquisa de campo do tipo survey e de natureza quantitativa. A pesquisa foi realizada em 112 escritórios de contabilidade situados na cidade de Belo Horizonte/MG e região metropolitana, registrados no Conselho Regional de Contabilidade (CRC/MG). Na análise de dados, utilizou-se a técnica bivariada para as questões referentes ao sistema integrado e ao controle interno e a técnica multivariada, utilizando-se do método Stepwise, para classificar os escritórios entre os quatro níveis de estágios de gerenciamento. Os resultados obtidos permitiram identificar o nível de integração entre as áreas sobre os aspectos de qualidade de dados, emissão de relatórios e controles operacionais e estratégicos, constatando-se o grau de utilização de controle interno e sistemas integrados.

Palavras-chave: Controle interno, Sistema de gerenciamento; Escritórios de contabilidade; Modelo de quatro estágios de Kaplan e Cooper

\section{Abstract}

This study examines the level of management and internal controls of accounting firms from the four-stage typology developed by Kaplan and Cooper (1998) to project management systems. In the methodology, we adopted the descriptive study, using field research on the type and quantitative survey. The research was conducted in 112 accounting firms located in the city of Belo Horizonte / MG and the metropolitan area, recorded in the Regional Accounting Council (CRC / MG). In data analysis, we used the technique for bivariate issues and the integrated internal control and the multivariate technique, using the stepwise method to rank the offices of the four levels of stage management. The results allowed to identify the level of integration between departments on aspects of data quality, reporting and strategic and operational controls, verifying the degree of utilization of internal control and integrated systems.

Keywords: Control; Management system; Accounting office; Kaplan and Cooper's four-stage model. 
Sistema de Gerenciamento e Controle Interno: uma Análise dos Escritórios de Contabilidade de Belo Horizonte/MG e Região Metropolitana a partir da Taxonomia de Kaplan e Cooper

\section{INTRODUÇÃ̃O}

$\mathrm{Na}$ prestação de serviços terceirizados de contabilidade, oferecer serviços com confiabilidade, qualidade e excelência no atendimento personalizado a cada perfil de cliente é o grande desafio dos escritórios. Além da complexidade dos serviços em face à grande variedade de clientes que os escritórios possuem, há também a dificuldade de manter atualizados os controles internos para execução das rotinas de escrituração em suas diferentes áreas.

Por sua vez, o aprimoramento das normas contábeis, e as novas tecnologias têm levado os escritórios a promoverem melhoramentos contínuos nos processos de gerenciamento e nos procedimentos das rotinas executadas no intuito de reduzir os custos, minimizar os erros e/ ou falhas e aumentar a confiabilidade nos serviços prestados. Os contratantes dos serviços contábeis, por essência da relação de custo benefício, podem fazer a opção pela contabilidade interna executada nas suas próprias dependências, utilizando o seu sistema de informação integrado, ou não; como também podem preferir que os serviços contratados sejam executados nas dependências da contratada, utilizando o banco de dados da mesma, sendo opcional o envio de arquivos para a integração de dados.

Em geral, os gestores das empresas contratantes utilizam as informações fornecidas pela contabilidade, como suporte para a tomada de decisão, análise e controle da atual situação patrimonial e planejamento estratégico de curto e longo prazo (WARREN; REVÉ; FESS, 2001). Além dos tradicionais relatórios financeiros, tais como: o balanço patrimonial, o demonstrativo de resultado, a demonstração das mutações do patrimônio líquido e o fluxo de caixa, existem vários outros demonstrativos gerencialmente elaborados de acordo com a necessidade individual e a complexidade de cada negócio.

Assim, apesar do constante esforço dos escritórios para se manterem atualizados, salientase que, devido ao grande volume de informações necessárias ao atendimento de suas principais rotinas, não seria surpreendente a existência, nessas organizações, de sistemas inadequados, com pouca consistência para o propósito de geração dos diferentes relatórios, acompanhamento do controle interno das transações, registro das informações e também para apoio ao processo decisório de seus clientes.

Para ampliação da fronteira do conhecimento sobre tal aspecto, investiga-se, neste estudo, o nível de gerenciamento dos controles internos e dos sistemas integrados nesses escritórios e busca-se evidenciar aspectos que os classificariam conforme proposições do modelo de quatro estágios desenvolvido por Kaplan e Cooper (1998).

De acordo com esse modelo, no estágio I caracterizam-se os escritórios que apresentam baixa confiabilidade na geração de relatórios financeiros e contábeis; no estágio II, estariam os escritórios que fornecem relatórios financeiros e contábeis periodicamente com certo grau de confiabilidade; já no estágio III, estariam os escritórios que utilizam sistemas informatizados para a geração dos relatórios financeiros e contábeis e utilizam esses dados para o controle operacional e gerencial; por fim, no estágio IV, observa-se a utilização de sistemas de informações integrados para a elaboração de todos os relatórios financeiros e contábeis que são utilizados para a tomada de decisão (KAPLAN; COOPER,1998). 


\section{REFERENCIAL TEÓRICO}

\subsection{Gerenciamento das empresas, sistema de informação e controle}

É vasta a literatura que trata do gerenciamento das empresas relacionando-o com a tomada de decisão, com as questões de planejamento estratégico e com o processo decisório. Entre os vários estudos sobre esse tema, citam-se Brodbeck, Rigoni e Canepa (2007); Silva e Lima (2007). Outros autores têm buscado relacioná-lo com a tecnologia da informação, caso de Graeml, Maciel e Macadar (2007); Brodbeck, Tonolli e Costa (2008); Passos e Ceita (2008); Graeml et al. (2008); Spelta e Albertin (2008). Já outros buscaram relacionar o gerenciamento com os diferentes tipos de serviços prestados pelas empresas, entre os quais citam-se Prado e Takaoka (2007); Sabbadini e Oliveira (2007); Joia e Magalhães (2007); Araújo e Figueiredo (2006).

Gerenciamento e Controle Organizacional são temas de grande afinidade, e alguns trabalhos iniciais foram importantes em sua inserção na academia. São eles: Davis (1928, 1940, 1951), que definiu o controle de gestão como sendo uma função orgânica da administração cujo objetivo é guiar uma empresa a partir da regulação de suas atividades; Dent (1934), que focou no ponto de vista do analista de orçamento, ao abordar as principais perspectivas do controle orçamentário; Glover e Maze (1937), que explicaram os instrumentos e métodos de controle como formas de avaliação de desempenho, por meio da utilização de padrões, relacionando controle de gestão à análise de custos; Rowland (1947), que procurou associar controle a planejamento, chamando a atenção para a forte relação existente entre essas variáveis. Merece destaque a pesquisa de Holden, Fish e Smith (1941), que evidenciaram o controle de gestão como sendo responsabilidade primária da alta direção em uma amostra de 31 empresas industriais. Os autores constataram, nesse estudo, que o controle de gestão é um processo que envolve, basicamente, três elementos: a) objetivos: determinar o que é desejado; b) procedimentos: planejar como e quando uma tarefa deve ser realizada, organização para determinar quem é responsável e padrões para determinar o que constitui bom desempenho e c) avaliação: para determinar o nível obtido de uma tarefa realizada.

Estudos de controles gerenciais têm ganhado atenção especial e estímulo nos trabalhos de pesquisas desenvolvidos nos últimos anos. É possivel encontrar pesquisas que abordaram a importância das variáveis que envolvem as práticas operacionais e o desempenho das empresas, entre os quais citam-se Brito, Duarte e Di Serio (2007). Há também trabalhos que procuraram associar os controles de gestão com a qualidade e a confiabilidade das informações e sistemas integrados, como Sordide, Costa e Grijó (2008) e Rodrigues (2008). Por sua vez, alguns trabalhos tentaram identificar a importância do controle interno como apoio para o gerenciamento das empresas, caso de Pereira (2004). Por fim, associando controle à auditoria interna foram identificados os trabalhos de Martin (2002), Oliveira (2004), Lunkes et. al. (2009) e Young (2009).

Em relação ao setor de prestação de serviços de contabilidade, denota-se a contribuição de alguns estudos, tais como: Goetz (1949), que examinou o controle de gestão do ponto de vista da contabilidade, interpretando o controle como um instrumento que garante a conformidade aos planos de negócios; Pereira (2004), que forneceu indícios da necessidade do controle interno para as operações executadas pelos escritórios mediante a execução de atividades de acordo com as especificidades de cada um; finalmente, Bordin e Saraiva (2005), que procuraram demonstrar 
como o controle interno poderia assegurar a integridade dos registros e das demonstrações contábeis, tornando assim, o processo decisório mais racional.

Entre outros aspectos, é reconhecido que os controles de gestão também possuem uma dimensão coletiva nas empresas, pois envolvem a participação de toda a equipe, e a maneira como as informações são utilizadas pelos diferentes tipos de usuários. Na visão de Horngren, Foster e Srikant (1997) o controle interno é visto não só como meio de se obter e utilizar as informações, para coordenar as decisões de planejamento e controle em uma empresa, mas também, para orientar o comportamento do empregado. Já para Mosimann e Fisch (1999), o principal objetivo do controle nas empresas é salvaguardar o patrimônio e definir o rumo da empresa, garantindo sua continuidade e o cumprimento de sua missão.

Acredita-se que um bom controle gerencial implantado contribui para o crescimento e a competitividade das empresas, assegurando-se que os recursos sejam obtidos e aplicados eficazmente na realização dos objetivos específicos das rotinas realizadas pelas diversas áreas (ANTHONY,1976; MERCHANT, 1997; HORNGREN; FOSTER; SRIKANT,1997). Para Merchant (1997), os sistemas de controle vão além de simples procedimentos gerenciais e operacionais, e assumem aspecto estratégico. Já para o gerenciamento dos escritórios de contabilidade, o controle gerencial é o mais adequado, por ter como foco as rotinas realizadas pelas áreas administrativa, contábil, fiscal e pessoal. Assim sendo, pressupõe-se que o controle interno implantado assegura para os gestores dos escritórios maior qualidade nas informações fornecidas e maior segurança nos serviços realizados, tendo como meta a diminuição dos erros e o aumento da confiabilidade.

No que diz respeito ao gerenciamento das informações, a contabilidade exerce um papel fundamental por meio da emissão de seus relatórios, pois um dos seus objetivos prover e fornecer informações úteis e confiáveis para auxiliar os gestores na tomada de decisão, principalmente em relação ao controle de gestão (MOSIMANN; FISCH, 1999).

As informações fornecidas pela contabilidade irão contribuir para o gerenciamento do desempenho operacional e estratégico das empresas. No entanto, isso é alvo de críticas lastreadas, principalmente, no argumento de que geralmente as informações contábeis são processadas pelas diversas áreas de um escritório e que, para maximizar sua utilidade, as informações devem ser processadas via sistemas integrados. Alberton, Limongi e Kruger (2004) chamam a atenção, porém, da necessidade de se ter um planejamento adequado, além de uma pesquisa com os diversos fornecedores de tais sistemas, sob o risco da integração não trazer contribuições para a melhoria dos processos da organização, quando mal implementada.

Padoveze (2004) recomenda que um sistema de informação contábil deve estar totalmente alinhado e integrado com os demais subsistemas de informação da empresa. Mas o sistema se torna um grande aliado no processo de tomada de decisão (VELLANI; RIBEIRO, 2009), quando passa a fornecer informações úteis em curto espaço de tempo. Segundo Theodoro (2006), os sistemas de informação e a controladoria estão intimamente ligados ao gerenciamento das empresas.

Para Oliveira (2002), o processo de transformação de dados que são utilizados na estrutura decisória da empresa assume um papel fundamental para o gerenciamento das informações que podem ser analisadas com base nos registros das informações passadas, geradas no presente, ou habilitando-se a possibilidade de projetá-las para o futuro, conforme 
interesse da administração.

Padoveze (2004) também argumenta que a utilização de um sistema gerencial de informações irá atingir seu objetivo de fornecer relatórios para a tomada de decisão, a partir da possibilidade de consolidação e aglutinação das informações, para obter uma melhor gestão de todas as áreas da empresa, proporcionando, assim, maior dinamismo do fluxo de informações. A geração e utilização das informações por meio de sistema de informação gerencial para o planejamento e o suporte nos processos de tomada de decisões fomentam as estratégias de curto e de longo prazo, o que, de acordo com Rezende (2003), facilitaria as empresas a trabalharem com situações de mudanças, constituindo-se, desse modo, um excelente instrumento de gestão.

Sobre tal aspecto, entende-se que as informações contábeis geradas pelos sistemas informatizados e aliadas aos controles de gestão são fatores relevantes para os gestores na tomada de decisão e principalmente no gerenciamento das empresas. Esta pesquisa não busca identificar um modelo conceitual dentro do enfoque sistêmico, mas o grau de integração dos diferentes escritórios de contabilidade pesquisados. Para tanto, apóia-se na abordagem metodológica do modelo de quatro estágios para identificar níveis de integração de sistemas apresentada por Kaplan e Cooper (1998).

\subsection{Modelo de quatro estágios de Kaplan e Cooper}

O modelo de quatro estágios para projetar sistemas de custos e desempenho surgiu na década de 70, por meio de estudos de Kaplan e Cooper em empresas que não usavam recursos informacionais capazes de contribuir para o gerenciamento adequado de custos e melhoria do desempenho operacional. Segundo Silva (2003) a primeira publicação que aborda esse modelo foi um artigo de Kaplan (1990) intitulado: "The Four-stage Model of cost System Design".

O modelo avalia quatro características que podem ser identificadas nos serviços de contabilidade prestados: a) utilização de sistemas de processamento de dados; b) definição de serviços de acordo com as expectativas dos clientes; c) aprimoramento contínuo na execução das rotinas em busca de qualidade, eficiência e rapidez; d) estruturação de processos eficientes e eficazes de serviços adequados ao perfil da sua carteira de clientes (KAPLAN; COOPER, 1998). Dessa forma, as empresas são classificadas de acordo com a análise do sistema de gerenciamento sobre os aspectos de qualidade de dados, relatórios financeiros, gastos com os clientes e o controle operacional e estratégico.

Neste estudo, consideraram-se os mesmos aspectos na análise de quatro estágios para identificar os níveis dos sistemas de gerenciamento dos escritórios de contabilidade, focando o processo de gestão da informação via sistema informatizado. No entanto, propõe-se uma adaptação ao modelo para acompanhar o gerenciamento dos escritórios de contabilidade a partir de suas especifidades com relação à estrutura, à utilização de sistemas informatizados na prestação de serviços e à integração entre as áreas contábil, fiscal, pessoal, administrativa, financeira e gerencial.

Em relação ao modelo original, esta proposta mantém a preocupação quanto aos aspectos dos sistemas como a qualidade de dados, os relatórios gerenciais e financeiros e o controle 
Sistema de Gerenciamento e Controle Interno: uma Análise dos Escritórios de Contabilidade de Belo Horizonte/MG e Região Metropolitana a partir da Taxonomia de Kaplan e Cooper

operacional e estratégico. No entanto, enquanto o modelo de Kaplan e Cooper (1998) foca os custos, o modelo adaptado tem como foco controle interno e o gerencimento das informações, Quadro 1.

\begin{tabular}{|c|c|c|c|c|}
\hline $\begin{array}{c}\text { Aspectos dos } \\
\text { sistemas }\end{array}$ & $\begin{array}{c}\text { Sistemas de } \\
\text { Estágios I } \\
\text { Falhos }\end{array}$ & $\begin{array}{c}\text { Sistemas de Estágios } \\
\text { II Relatórios } \\
\text { Financeiros }\end{array}$ & $\begin{array}{c}\text { Sistemas de Estágios } \\
\text { III Especializados }\end{array}$ & $\begin{array}{c}\text { Sistemas de Estágios } \\
\text { IV Integrados }\end{array}$ \\
\hline $\begin{array}{c}\text { Qualidade } \\
\text { de dados }\end{array}$ & $\begin{array}{c}\text { Escrituração } \\
\text { manual, com } \\
\text { muitos erros } \\
\text { e grandes } \\
\text { variações nos } \\
\text { saldos das } \\
\text { contas. }\end{array}$ & $\begin{array}{c}\text { Utilização de sistemas } \\
\text { informatizados sem } \\
\text { nenhuma integração } \\
\text { de dados. }\end{array}$ & $\begin{array}{c}\text { Utilização de sistemas } \\
\text { integrados entre as áreas } \\
\text { da contabilidade, fiscal e } \\
\text { pessoal do escritório de } \\
\text { contabilidade. }\end{array}$ & $\begin{array}{c}\text { Utilização de sistemas } \\
\text { integrados entre todas } \\
\text { as areas do escritório } \\
\text { de contabilidade, } \\
\text { inclusive as áreas do } \\
\text { administrativo financeiro } \\
\text { e gerencial. }\end{array}$ \\
\hline $\begin{array}{c}\text { Relatórios } \\
\text { financeiros } \\
\text { contábeis } \\
\text { externos }\end{array}$ & $\begin{array}{c}\text { Inadequados, } \\
\text { não refletem } \\
\text { a realidade do } \\
\text { escritório. }\end{array}$ & $\begin{array}{c}\text { Inadequados, não } \\
\text { possuem frequência na } \\
\text { emissão. }\end{array}$ & $\begin{array}{c}\text { Adequados, } \\
\text { relatórios mensais ou } \\
\text { trimestrais. }\end{array}$ & $\begin{array}{c}\text { Adequados, } \\
\text { relatórios emitidos } \\
\text { frequentemente e } \\
\text { utilizados para a tomada } \\
\text { de decisão. }\end{array}$ \\
\hline $\begin{array}{c}\text { Gastos com } \\
\text { cliente }\end{array}$ & $\begin{array}{c}\text { Inadequados } \\
\text { Não existe } \\
\text { controle. }\end{array}$ & $\begin{array}{c}\text { Imprecisos, há alguns } \\
\text { controles das receitas, } \\
\text { dos custos e despesas, } \\
\text { porém não são } \\
\text { utilizados. }\end{array}$ & $\begin{array}{c}\text { Adequados, há controles } \\
\text { gerenciais das receitas, } \\
\text { despesas e custos de } \\
\text { forma total. }\end{array}$ & $\begin{array}{c}\text { Adequados aos } \\
\text { controles gerenciais } \\
\text { individuais por cliente } \\
\text { de cada receita, custos e } \\
\text { despesas. }\end{array}$ \\
\hline $\begin{array}{c}\text { Controle } \\
\text { operacional } \\
\text { estratégico }\end{array}$ & $\begin{array}{c}\text { Inadequados } \\
\text { Não existe } \\
\text { controle }\end{array}$ & $\begin{array}{c}\text { Controles gerenciais } \\
\text { limitados e } \\
\text { desatualizados. }\end{array}$ & $\begin{array}{c}\text { Controles gerenciais } \\
\text { obtidos através do } \\
\text { sistema, porém não } \\
\text { são utilizados com } \\
\text { frequência. }\end{array}$ & $\begin{array}{c}\text { Conitidos frequentemente } \\
\text { e utilizados para a } \\
\text { tomada de decisão. }\end{array}$ \\
\hline
\end{tabular}

Quadro 1- Modelo de quatro estágios para projetar um sistema de gerenciamento dos escritórios de contabilidade.

Fonte: Adaptado de Kaplan e Cooper (1998, p. 23).

\section{METODOLOGIA}

Buscando verificar em qual estágio de integração estão os escritórios de contabilidade, a partir da proposta de Kaplan e Cooper (1998), em termos de gerenciamento dos controles internos e dos sistemas de informações, foi realizada uma pesquisa junto aos escritórios registrados no CRC/MG de Belo Horizonte e região metropolitana. Na metodologia, adotou-se o estudo descritivo, por meio de pesquisa de campo do tipo survey e de natureza quantitativa. Na ocasião da pesquisa, a população era constituída de 1.172 escritórios de contabilidade registrados no $\mathrm{CRC} / \mathrm{MG}$ na região de Belo Horizonte. Deste número, foi selecionada uma amostra aleatória de 112 escritórios. A técnica de amostragem foi probabilística e a margem de erro correspondente a um desvio é de $4,74 \%$ e para dois desvios ( $95,5 \%$ de probabilidade) é de $9,44 \%$.

Os dados foram coletados pela aplicação de questionários respondidos pelos sócios contadores que atuam como administradores dos escritórios de contabilidade. Pressupõe-se que esses respondentes conhecessem em profundidade todas as dimensões pesquisadas bem como as variáveis que estariam presentes nos processos de gerenciamento. $\mathrm{O}$ questionário utilizado continha 52 questões divididas em três blocos, usando questões de múltipla escolha e escala do tipo Likert. No primeiro bloco, procurou-se delimitar o perfil e a estrutura dos escritórios de contabilidade. As perguntas do segundo bloco tinham como objetivo analisar as características do controle interno operacional, do sistema integrado e o processo de gestão da informação 
para tomada de decisão dos sócios contadores dos escritórios de contabilidade. Finalmente, no terceiro bloco, procurou-se identificar em qual dos quatros níveis de gerenciamento estão os escritórios de contabilidade de Belo Horizonte/MG e região metropolitana, a partir da abordagem do modelo de quatro estágios de Kaplan e Cooper (1998).

A análise de dados foi realizada em três etapas, tendo cada uma procedimentos específicos. Na primeira etapa, apresentam-se estatísticas descritivas da análise exploratória inicial da base de dados. Nesta etapa, foram construídas tabelas cruzadas fixando sempre a relação conjunta de sistema integrado e controle interno com as demais variáveis qualitativas do questionário. $\mathrm{Na}$ segunda etapa, análise multivariada, buscou-se averiguar o relacionamento conjunto das variáveis que são importantes para explicar as variáveis-respostas "controle interno" e "sistema integrado", utilizando-se como medidas de associação duas opções de Qui-quadrado $\left(\chi^{2}\right)$ para confirmação dos resultados a serem expostos: Pearson e o teste de razão de verossimilhança.

$\mathrm{Na}$ sequência, foi realizada a escolha das variáveis explicativas mais relevantes, estatisticamente, utilizando o método Stepwise. Foi possível analisar todas variáveis explicativas estatisticamente significantes conjuntamente e, além disso, identificar as categorias de cada variável explicativa qualitativa que são mais importantes para explicar o comportamento dos níveis de integração e de controle interno dos escritórios de contabilidade. Para avaliar a qualidade do ajuste da regressão ordinal que possibilitou identificar as variáveis explicativas, foi usado o coeficiente de determinação ou pseudo $R^{2}$ de McFadden que corresponde à proporção de variação explicada da variável dependente pelas variáveis explicativas. Quanto maior o seu valor, mais a variabilidade da variável dependente, ou seja, sistema integrado ou controle interno, é explicada pela variabilidade das variáveis explicativas. Para escolha do modelo final da regressão ordinal foi utilizado o critério de informação de Akaike (AIC).

De posse das variáveis explicativas estatisticamente significantes, seja com efeitos negativos ou positivos sobre a no nível de integração e de controle interno dos escritórios de contabilidade analisados, identificou-se em quais fases os mesmos se encontravam de acordo com o terceiro bloco de perguntas do questionário. O objetivo era verificar se tais variáveis determinariam ou não nos estágios classificados pelo modelo de Kaplan e Copper (1998), que estes escritórios se encontravam.

\section{ANÁLISE E DISCUSSÃO DOS RESULTADOS}

\subsection{Estrutura e o Perfil dos Escritórios de Contabilidade}

Os dados obtidos permitem uma análise quantitativa da estrutura e o perfil dos escritórios de contabilidade. Assim, observa-se que 27,7\% dos escritórios não possuem controle interno implantado, $57,1 \%$ possuem parcialmente e apenas $15,2 \%$ possuem controle interno completamente implantado, conforme indicado pelos respondentes. Em relação aos sistemas integrados, 38,4\% dos escritórios dizem não possuir sistemas gerenciais integrados, $45,5 \%$ são integrados parcialmente e $16,1 \%$ haviam integrado por completo seus sistemas.

$\mathrm{Na}$ Tabela 1 apresenta-se a análise conjunta das variáveis categóricas, cruzando, "proporção de áreas integradas", com "existência de controle interno" e "suporte para tomada de decisão". Do total da amostra, 37,32\% afirmam não possuir nenhuma dessas categorias. Por outro lado, $27,23 \%$ dos escritórios afirmam possuir todas as três categorias. 
Sistema de Gerenciamento e Controle Interno: uma Análise dos Escritórios de Contabilidade de Belo Horizonte/MG e Região Metropolitana a partir da Taxonomia de Kaplan e Cooper

Tabela 1- Proporção de áreas integradas, com controle interno e suporte utilizado para tomada de decisão

\begin{tabular}{c|c|cc}
\hline & Não possui & Parcial & Completo \\
\hline Áreas integradas & 0,3839 & 0,4554 & 0,1607 \\
\hline Controle interno implantado & 0,2768 & 0,5714 & 0,1518 \\
\hline Suporte para tomada de decisões & 0,3839 & 0,3147 & 0,3013 \\
\hline Variáveis conjuntas & 0,3732 & 0,3545 & 0,2723 \\
\hline \multicolumn{4}{r}{ Fonte: Dados da pesquisa }
\end{tabular}

$\mathrm{Na}$ Tabela 2, apresentam-se os dados do controle interno e sistemas integrados e respectivas associações e correlações entre as variáveis categóricas de perfil estrutural que caracterizam os escritórios. Segundo os resultados, observa-se que o tempo médio (18 anos) é maior nos escritórios que possuem sistema integrado parcial e não possuem controle interno, e menor (11,5 anos) nos que não possuem controle interno e sistema integrado. Para os escritórios que possuem sistema integrado completo e controle interno parcial, o tempo de vida é aproximadamente de 13 anos.

Em relação à quantidade média de sócios, conforme indicado pelos respondentes, é maior em escritórios que possuem sistema integrado parcial e não possuem controle interno $(2,6)$ e menor nos que não possuem sistema integrado e possuem controle interno completamente implantado $(2,12)$. Já a quantidade média de funcionários $(14,1)$ é maior em escritórios que possuem sistema integrado parcialmente implantado e controle interno implantado por completo, e menor $(6,4)$ em escritórios que possuem sistema integrado completamente implantado e não possuem controle interno. Evidencia-se um número reduzido de funcionários em relação aos escritórios que possuem sistema integrado parcialmente; é possível também perceber que o nível de controle interno implantado apresenta associação com o número de funcionários desses escritórios.

Quanto aos níveis de qualificação condicionados à categoria "sócios" e "funcionários" e associada à existência, ou não, de sistema integrado e controle interno, os resultados mostram que, dentre os que não possuem sistema integrado e controle interno, a porcentagem média é superior entre os funcionários que têm qualificação técnica em contabilidade $(70 \%)$ e entre os sócios com a mesma qualificação $(59,3 \%)$, Tabela 2 . Observa-se também que, dentre os escritórios de contabilidade que possuem sistema integrado completo e ausência de controle interno implantado, no grupo dos sócios, a maior porcentagem média $(56,6 \%)$ é de estudantes de ciências contábeis. Já no grupo dos funcionários, a maior porcentagem é para o nível técnico $(76 \%)$ e a menor é para os funcionários graduados e pós-graduados em contabilidade. Nos escritórios de contabilidade que possuem sistema integrado parcial e controle interno implantado por completo, no grupo dos funcionários, a maior porcentagem média ocorre para o nível técnico $(42,7 \%)$ e a menor em funcionários pós-graduados $(8,8 \%)$. Já no grupo dos sócios, verifica-se a maior média para sócios graduados em ciências contábeis $(38,8 \%)$.

Com relação à atividade dos clientes, observa-se que a porcentagem média é maior no setor de serviços do que nas outras atividades e menor no terceiro setor (ONGs, etc.). No setor de serviços destacam-se os escritórios que não têm sistema integrado e têm controle interno parcial, pois, dentre estes, a maior porcentagem média $(47,8 \%)$ ocorre nesse setor e a menor no terceiro setor $(2,1 \%)$. Nos escritórios que possuem sistema integrado parcial e controle interno completamente implantado, a maioria dos clientes é do ramo de prestação de serviços $(46,4 \%)$ seguidos pelas empresas comerciais (37,2\%). Para os escritórios que não possuem nem sistema integrado e ausência controle interno, a maior porcentagem média ocorre nos escritórios que os 
clientes também pertencem ao setor de serviços $(38,1 \%)$, ao setor de comércio $(36,8 \%)$ e menor, ao terceiro setor $(4,3 \%)$. Nesse caso, é possível aferir que nem a implantação do controle interno e nem na utilização de sistemas integrados está associada atividade econômica dos clientes. Ou seja, não se pode pressupor que os escritórios sejam estruturados em função da complexidade da prestação de serviços.

Com relação ao enquadramento fiscal federal dos clientes, observa-se que os optantes pelo simples nacional são os que possuem maior média em relação aos demais. Já os escritórios que possuem sistema integrado parcial e controle interno parcial, a maior porcentagem média ocorre naqueles que possuem clientes cujo regime de tributação é o simples nacional $(50,3 \%)$ e a menor para os clientes enquadrados como imunes/isentos (3,1\%). Este último grupo possui menor média dentre todos os demais tipos e é menor nos escritórios que não possuem sistema integrado e possuem controle interno implantado (1,3\%). Em termos gerenciais, não se tem indícios de que as atividades que envolvam atendimento ao cliente, em diferentes demandas, provoquem a necessidade de aumento e integração dos sistemas para geração de informações e controle das rotinas dos escritórios.

Por outro lado, foram observados alguns artefatos contábeis que influenciam no gerenciamento das informações que são utilizados como ferramentas auxiliares na tomada de decisão dos escritórios de contabilidade. Entre outros, consideram-se inicialmente as demonstrações contábeis elaboradas pelos contadores de acordo com a legislação vigente, seja através da contabilidade gerencial ou simplesmente como fonte de informações para o público externo (Tabela 3). Nesse aspecto, a preocupação foi identificar a frequência de emissão e elaboração das demonstrações e não como elas são utilizadas no suporte à tomada de decisão.

Tabela 2- Médias das quantidades e das porcentagens das variáveis condicionadas à existência ou não de sistema integrado e controle interno implantado.

\begin{tabular}{l|c|c|c|c|c|c|c|c}
\hline Sistema integrado & $\tilde{N}$ p. & Parcial & Completo & $\tilde{N}$ p. & Parcial & Completo & N p. & Parcial \\
\hline Controle interno & $\tilde{N}$ p. & $\tilde{N}$ p. & $\tilde{N}$ p. & Parcial & Parcial & Parcial & Completo & Completo \\
\hline Tempo de vida & 11,5 & 18 & 13,2 & 12,6 & 12,8 & 13,6 & 12,2 & 16,1 \\
\hline Quantidade de sócios & 2,5 & 2,6 & 2,2 & 2,57 & 2,4 & 2,5 & 2,1 & 2,4 \\
\hline Técnico em contabilidade & 59,3 & 46 & 26,6 & 32,42 & 26 & 44,2 & 31,2 & 18,8 \\
\hline Estudante contabilidade & 12,5 & 27 & 56,6 & 16,7 & 20,7 & 11,5 & 43,7 & 26,6 \\
\hline Graduado em contabilidade & 18,7 & 27 & 6,8 & 35 & 36 & 34,6 & 18,7 & 38,8 \\
\hline Pós-graduado & 9,38 & 0 & 10 & 15,7 & 17,1 & 9,6 & 6,25 & 15,5 \\
\hline Quantidade de funcionários & 9,3 & 12,8 & 6,4 & 7,4 & 10,4 & 10,3 & 10 & 14,1 \\
\hline Técnico em contabilidade & 70 & 63 & 76 & 71,3 & 54,4 & 51,1 & 67,5 & 42,7 \\
\hline Estudante de contabilidade & 26,2 & 34 & 24 & 17,8 & 33,2 & 32,3 & 23,7 & 33,8 \\
\hline Graduado em contabilidade & 3,7 & 3 & 0 & 8,6 & 10 & 14,2 & 7,5 & 14,4 \\
\hline Pós-graduado & 0 & 0 & 0 & 2,1 & 2,2 & 2,3 & 1,2 & 8,8 \\
\hline Clientes setor: Serviços & 38,1 & 36,5 & 44 & 47,8 & 44,8 & 33,8 & 41,2 & 46,4 \\
\hline Clientes setor: Comércio & 36,8 & 46 & 38 & 38,6 & 37,8 & 41,1 & 42,5 & 37,2 \\
\hline Clientes setor: Indústria & 20,6 & 16 & 15 & 11,3 & 13,9 & 21,9 & 15 & 13,1 \\
\hline Clientes setor: Terceiro Setor & 4,3 & 1,5 & 3 & 2,1 & 3,4 & 3 & 1,2 & 3,2 \\
\hline Regime fiscal clientes: Simples & 40,6 & 43,5 & 47 & 45,2 & 50,3 & 35,3 & 46,8 & 48,7 \\
\hline Regime fiscal: Lucro presumido & 36,2 & 39 & 34 & 37,6 & 31,4 & 38,8 & 36,2 & 34 \\
\hline Regime fiscal: Lucro real & 19,3 & 16 & 16 & 15,2 & 15,1 & 22,6 & 15,6 & 15,4 \\
\hline Regime fiscal: Imune/isento & 3,75 & 1,5 & 3 & 1,8 & 3,1 & 3,1 & 1,3 & 1,7 \\
\hline N p. sigifia
\end{tabular}

$\widehat{\mathrm{N}}$ p. significa não possui 
Na visão de Kaplan e Cooper (1998) as organizações de serviços precisam identificar defeitos em seus procedimentos internos capazes de afetar a qualidade dos serviços. Mas, além da informação inadequada, deve-se observar com que frequência os resumos financeiros são emitidos para garantia dos procedimentos operacionais internos. Nota-se, por exemplo, que o orçamento, apesar de bastante enfatizado na academia como um instrumento dos principais instrumentos de controle gerencial, foi indicado pelos respondentes como uma ferramenta não utilizada pela maioria dos escritórios. Dos resultados obtidos, verificou-se que as demonstrações que são menos utilizadas pelos escritórios de contabilidade são: DMPL $(95,5 \%)$ e orçamento $(96,4 \%)$, Tabela 3.

Tabela 3 - Frequência média de emissão dos demonstrativos contábeis e financeiros

\begin{tabular}{l|c|c|c|c|c}
\hline \multicolumn{1}{c|}{ Demonstrativos } & Não utiliza & Diária & Mensal & Trimestral & Anual \\
\hline Balancete & 0,000 & 0,071 & 0,223 & 0,357 & 0,348 \\
\hline Balanço Patrimonial & 0,009 & 0,000 & 0,125 & 0,286 & 0,580 \\
\hline Demonstrativo de Resultado & 0,009 & 0,000 & 0,170 & 0,277 & 0,545 \\
\hline DFC & 0,429 & 0,152 & 0,107 & 0,063 & 0,250 \\
\hline DMPL & $\mathbf{0 , 9 5 5}$ & 0,000 & 0,000 & 0,009 & 0,036 \\
\hline Orçamento & $\mathbf{0 , 9 6 4}$ & 0,009 & 0,009 & 0,000 & 0,018 \\
\hline
\end{tabular}

Todos os escritórios de contabilidade indicaram utilizar o "balancete de verificação", sendo sua periodicidade de emissão diária (7,14\%), mensal (22,32\%), trimestralmente $(35,7 \%)$, seguidos da emissão anual (34,8\%). Observa-se, no entanto, que a emissão dos demonstrativos contábeis "balanço patrimonial" (58,0\%) e "demonstrativo de resultado" (54,5\%) acompanham a contabilidade para fins fiscais e não para fins gerenciais na maioria desses escritórios. Em geral, os resultados mostram que as informações não estão sendo utilizadas para controle operacional de curto prazo.

\subsection{Resultados da regressão ordinal}

Após a análise descritiva, foram encontradas as associações multivariadas com o intuito de analisar se as características dos escritórios de contabilidade explicam, de maneira conjunta, o nível de integração ou nível de controle interno implantado. Para conclusão de tal objetivo foi estimada a regressão ordinal posto que as variáveis dependentes são de natureza qualitativa ordinais. O método Stepwise foi utilizado para se escolher quais as principais variáveis que deveriam estar contidas no modelo. Identificadas as variáveis que produziram melhores ajustes, as mesmas foram unidas em um único modelo final. Sabe-se que, diante da presença de multicolinearidade, os erros-padrão dos coeficientes ficam alterados, e, em casos extremos, impossibilita-se até mesmo a estimação dos coeficientes devido à singularidade da matriz de variáveis explicativas. Dessa forma, verificou-se a forte presença de multicolinearidade entre variáveis explicativas do modelo por meio do Variance Inflation Factor (VIF).

Após a utilização do método Stepwise e avaliação dos VIFs, optou-se por retirar do conjunto as variáveis "elaboração de relatórios gerenciais e orçamento" quando a variável explicada era o sistema integrado dos escritórios. Também foram retiradas as variáveis "relatórios 
integrados" e "tempo de existência" do escritório por não serem estatisticamente significativas nem mesmo a $10 \%$. No caso de variáveis categóricas, basta uma categoria ser significativa para que todas as demais devam ser mantidas no modelo para efeito de comparação. A Tabela 4 contém os resultados estimados para explicar a variável sistema integrado.

Tabela 4- Resultados estimados para a variável explicada sistema integrado.

\begin{tabular}{|c|c|c|c|}
\hline & Coeficiente & Erro-padrão & P-valor \\
\hline Quantidade de funcionários técnicos em contabilidade & $-0,016$ & 0,009 & 0,062 \\
\hline Não possui escrituração manual nas áreas administrativa e financeira & 4,644 & 1,189 & 0,000 \\
\hline Não possui escrituração manual na área gerencial & 2,777 & 1,244 & 0,026 \\
\hline Utiliza pouco a intuição na tomada de decisão & $-1,165$ & 0,647 & 0,072 \\
\hline Utiliza muito a intuição na tomada de decisão & $-2,230$ & 0,669 & 0,001 \\
\hline Utiliza pouco a pesquisa de mercado para tomada de decisão & 1,685 & 0,812 & 0,038 \\
\hline Utiliza muito a pesquisa de mercado para tomada de decisão & 0,073 & 1,512 & 0,961 \\
\hline Utiliza pouco a opinião dos clientes na tomada de decisão & $-1,587$ & 0,583 & 0,007 \\
\hline Utiliza muito a opinião dos clientes na tomada de decisão & 0,057 & 0,627 & 0,928 \\
\hline Utiliza pouco o banco de dados do escritório para tomada de decisão & 2,311 & 1,364 & 0,090 \\
\hline Utiliza muito o banco de dados do escritório para tomada de decisão & 0,663 & 1,315 & 0,614 \\
\hline $\begin{array}{l}\text { Utiliza pouco o sistema de informação gerencial para tomada de } \\
\text { decisão }\end{array}$ & $-0,405$ & 0,598 & 0,498 \\
\hline $\begin{array}{l}\text { Utiliza muito o sistema de informação gerencial para tomada de } \\
\text { decisão }\end{array}$ & 1,539 & 0,602 & 0,010 \\
\hline Utiliza pouco, planilhas elaboradas no Excel para tomada de decisão & 0,861 & 0,507 & 0,090 \\
\hline Utiliza muito, planilhas elaboradas no Excel para tomada de decisão & 1,895 & 0,704 & 0,007 \\
\hline Elabora diariamente o fluxo de caixa & 1,244 & 0,703 & 0,076 \\
\hline Elabora mensalmente o fluxo de caixa & $-1,167$ & 0,792 & 0,141 \\
\hline Elabora trimestralmente o fluxo de caixa & 0,791 & 1,045 & 0,449 \\
\hline Elabora anualmente o fluxo de caixa & 0,533 & 0,565 & 0,345 \\
\hline Intercepto 1 & 5,900 & 2,224 & 0,008 \\
\hline Intercepto 2 & 9,750 & 0,144 & 0,000 \\
\hline \multicolumn{4}{|l|}{ Pseudo r2 de McFadden: 34,69} \\
\hline AIC: 191,1541 & & & \\
\hline
\end{tabular}

Dos resultados obtidos, observou-se que os níveis de integração em escritórios que possuem muitos funcionários com nível de qualificação técnico em contabilidade são menores, que utilizam a intuição para tomar decisões, quanto à atitude de concorrentes, em relação aos que não a utilizam. Os níveis de integração também são menores nos escritórios que utilizam pouco as ideias dos clientes como suporte às decisões gerenciais, em relação aos que não utilizam. Das variáveis descritivas que foram estatisticamente significativas e que exercem efeito negativo sobre os níveis de integração dos escritórios, a que possui maior influência devido ao valor numérico de seu coeficiente é a variável tomada de decisão com base na intuição.

Das variáveis que exercem efeitos positivos sobre o nível de integração das empresas, dentre as estatisticamente significativas a $10 \%$, destacam-se a não utilização de escrituração manual nas áreas administrativa, financeira e gerencial. Dessa forma, conclui-se que os controles 
Sistema de Gerenciamento e Controle Interno: uma Análise dos Escritórios de Contabilidade de Belo Horizonte/MG e Região Metropolitana a partir da Taxonomia de Kaplan e Cooper

manuais tendem a reduzir nas áreas administrativas e gerenciais quando o nível de integração tende a ser maior. Nestes termos, pode-se argumentar que o grau de integração de tais áreas seja essencial aos processos de integração desses escritórios. Principalmente a área administrativa, pois proporciona uma percepção de que os controles estejam mais eficientes.

Para as demais variáveis estatisticamente significativas a $10 \%$, os resultados indicam que os escritórios de contabilidade que utilizam pouco a pesquisa de mercado, em relação aos que nunca utilizam tendem a aumentar o nível de integração. Da mesma forma, escritórios que utilizam banco de dados tendem a aumentar o nível de integração em comparação aos que não utilizam, e os que também utilizam muito os sistemas de informação também tendem a aumentar o nível de integração em relação aos que não utilizam. Curiosamente, os escritórios que utilizam planilhas em Excel com pouca ou muita frequência para dar suporte às decisões no gerenciamento da organização contábil possuem maior nível de integração. Isso pode indicar falhas ainda existentes no processo de integração ou, que sejam utilizados controles paralelos até os sistemas atingiram maior confiabilidade na geração dos relatórios. Por fim, escritórios que utilizam fluxo de caixa diário, em relação aos que não utilizam, tendem a ter maiores níveis de integração, o que sugere um maior nível de informações que são utilizadas para a tomada de decisão a partir dos relatórios gerados pelo sistema de informação integrado entre as áreas, especificamente a administrativa e a financeira.

O mesmo procedimento adotado quando a variável resposta era o sistema integrado foi também adotado para a variável controle interno. Desse modo, verificou-se a forte presença de multicolinearidade entre as variáveis explicativas do modelo por meio do Variance Inflation Factor (VIF). Após a utilização do método Stepwise e avaliação dos VIF's, optou-se por retirar a variável funcionários graduados em contabilidade. Também retiraram-se as variáveis "utilização nenhum relatório gerencial informatizado", "quantidade de sócios e funcionários estudantes de contabilidade", "quantidade de sócios graduados em contabilidade", por não serem estatisticamente significativas nem mesmo a $10 \%$.

Quanto aos resultados obtidos, conforme Tabela 5, inicialmente observou-se que as variáveis que se relacionam negativamente ao controle interno são quantidades de funcionários técnico em contabilidade - que apresentam pouca influência, e quantidade de clientes. Nesse caso, a redução nos coeficientes desses dois itens indicaria uma tendência a aumentar o controle interno nos escritório. Especificamente, em relação ao número de cliente, poder-se-ia pressupor que tanto a estrutura, quanto a necessidade de controle das rotinas operacionais dos escritórios seria correlacionada a essa variável.

Dentre as variáveis estatisticamente significantes, a “elaboração de relatórios gerenciais via sistemas informatizados" tende a reduzir a necessidade de uso do controle interno implantado. Já na tomada de decisão, há indícios de que quanto maior o benchmarking das ações junto aos concorrentes, mais propício estará o escritório em aumentar o controle interno.

A variável de maior impacto é a "elaboração de orçamento", indicando que os escritórios que utilizam diariamente esse instrumento contábil em relação aos escritórios que não o utilizam, tendem a reduzir, em média, o controle interno implantado para as áreas administrativa e financeira, gerencial, fiscal, pessoal e contábil.

As variáveis que tendem, em média, a aumentar o nível de controle interno nos escritórios de contabilidade são a "escrituração manual" nas áreas gerenciais, administrativas e financeiras, a freqüência de emissão dos relatórios gerenciais e financeiros. Dentre essas, é possível perceber que a variável de maior influência no aumento do nível de controle interno dos escritórios é 
a "elaboração do demonstrativo de resultado". Vale observar que os valores positivos para os coeficientes estimados aumentam na medida em que aumenta a periodicidade de emissão desse relatório. Já, ao nível das variáveis que são utilizadas como suporte para tomada de decisões no gerenciamento da organização contábil, evidenciou-se que a "opinião dos funcionários" é pouco utilizada e as "consultas na internet" influenciam positivamente nas ações de controle.

Tabela 5- Resultados estimados para a variável explicada controle interno.

\begin{tabular}{|c|c|c|c|}
\hline & Coeficiente & Erro padrão & P-valor \\
\hline Quantidade de funcionários técnicos em contabilidade & $-0,030$ & 0,012 & 0,008 \\
\hline Escritórios com até 50 clientes & $-1,284$ & 0,670 & 0,055 \\
\hline Escritórios ente 51 a 100 clientes & $-0,406$ & 0,671 & 0,545 \\
\hline Clientes do escritório pertencentes ao segmento industrial & $-0,039$ & 0,022 & 0,080 \\
\hline Não possui escrituração manual nas áreas administrativa e financeira & 2,259 & 1,093 & 0,039 \\
\hline Não possui escrituração manual na área gerencial & 3,986 & 1,300 & 0,002 \\
\hline Utiliza pouco relatório gerencial elaborados de sistemas informatizado & $-3,285$ & 0,851 & 0,000 \\
\hline Utiliza muito relatório gerencial elaborados de sistemas informatizado & $-4,485$ & 1,181 & 0,000 \\
\hline Utiliza pouco as ações dos concorrentes na tomada de decisão & $-2,242$ & 0,839 & 0,008 \\
\hline Utiliza muito as ações dos concorrentes na tomada de decisão & $-0,314$ & 1,764 & 0,859 \\
\hline Utiliza pouco a opinião dos clientes na tomada de decisão & $-1,362$ & 0,696 & 0,050 \\
\hline Utiliza muito a opinião dos clientes na tomada de decisão & $-2,044$ & 0,768 & 0,008 \\
\hline Utiliza pouco a opinião dos funcionários na tomada de decisão & 1,920 & 0,728 & 0,008 \\
\hline Utiliza muito a opinião dos funcionários na tomada de decisão & 0,718 & 0,788 & 0,363 \\
\hline Utiliza pouco, relatórios emitidos pelo sistema integrado & 1,594 & 0,765 & 0,037 \\
\hline Utiliza muito, relatórios emitidos pelo sistema integrado & 2,202 & 0,838 & 0,009 \\
\hline Utiliza pouco o sistema de informação gerencial para tomada de decisão & 1,392 & 0,696 & 0,045 \\
\hline Utiliza muito o sistema de informação gerencial para tomada de decisão & 2,355 & 0,776 & 0,002 \\
\hline Utiliza pouco, consultas na internet para tomada de decisão & 2,337 & 0,780 & 0,003 \\
\hline Utiliza muito, consultas na internet para tomada de decisão & 2,443 & 0,788 & 0,002 \\
\hline Elabora mensalmente o demonstrativo de resultado & 23,546 & 0,799 & 0,000 \\
\hline Elabora trimestralmente o demonstrativo de resultado & 21,148 & 0,694 & 0,000 \\
\hline Elabora anualmente o demonstrativo de resultado & 20,484 & 0,615 & 0,000 \\
\hline Elabora diariamente o orçamento & $-18,779$ & 0,000 & 0,000 \\
\hline Elabora mensalmente o orçamento & $-5,011$ & 3,552 & 0,158 \\
\hline Elabora anualmente o orçamento & 4,585 & 3,130 & 0,143 \\
\hline Intercepto 1 & 23,673 & 15,147 & 0,000 \\
\hline Intercepto 2 & 28,703 & 214,700 & 0,000 \\
\hline \multicolumn{4}{|l|}{ Pseudo r2 de McFadden: 42,57 } \\
\hline AIC: 179,6902 & & & \\
\hline
\end{tabular}

\subsection{O Sistema de Gerenciamento dos Escritórios de Contabilidade de Acordo com a Abordagem do Modelo de Kaplan e Cooper (1998)}

Para finalizar a análise dos resultados, nessa seção apresenta-se a abordagem do modelo de quatro estágios desenvolvidos por Kaplan e Cooper (1998) para categorizar os níveis dos sistemas de gerenciamento dos escritórios de contabilidade.

Quanto aos resultados, verificou-se que, do total de 112 escritórios, 32,84\% deles estão no estágio I. Esse estágio caracteriza-se por conter escritório que apresentam baixa confiabilidade na geração de relatórios financeiros e contábeis; $30,55 \%$ estão no estágio II, que define os escritórios 
Sistema de Gerenciamento e Controle Interno: uma Análise dos Escritórios de Contabilidade de Belo Horizonte/MG e Região Metropolitana a partir da Taxonomia de Kaplan e Cooper

que emitem relatórios financeiros e contábeis periodicamente com certo grau de confiabilidade; $23,35 \%$ estão no estágio III, que inclui os escritórios que utilizam sistemas informatizados para a geração dos relatórios financeiros e contábeis e utilizam esses dados para o controle operacional e gerencial e 13,34\% estão no estágio IV que indica a utilização de sistemas de informações integrados para a elaboração de todos os relatórios financeiros e contábeis que são utilizados no processo decisório (KAPLAN; COOPER,1998).

A maioria dos escritórios de contabilidade está estágio I e II $(63,39 \%)$ e o restante, nos estágios II e III (36,61\%). No entanto, foi percebida neste estudo uma tendência de migração para os estágios III e IV. Pode-se aferir que esses escritórios possuem características semelhantes a empresas, no que tange a necessidade de garantir adequados sistemas gerenciais. Entretanto, devem-se fazer ressalvas para generalizações desses resultados, pois provavelmente existem suposições diferentes quanto à percepção, por parte dos respondentes, em relação à qualidade e níveis de integração dos sistemas. Mas por outro lado, essas evidências tiveram como base as premissas do modelo de gerenciamento de Kaplan e Cooper (1998). Motivado pelo mesmo interesse, Silva (2003) também observou que $80 \%$ das indústrias de transformação do estado de Pernambuco estavam entre o estágio I e II do modelo.

Finalmente, limitando-se o universo de variáveis apenas àquelas que exercem efeitos positivos ou negativos no nível de integração dos escritórios de contabilidade, foi feita a classificação para identificar em qual dos quatro estágios os mesmos se encontravam. Uma consideração inicial diz respeito à variável "técnico em contabilidade" que teve de ser categorizada em quatro níveis, para melhor visualização de cada fase do modelo, Tabela 5.

Tabela 5 - Estágios dos escritórios de contabilidade de acordo com as variáveis estatisticamente significativas para explicar o sistema de informação integrado

\begin{tabular}{l|c|c|c|c}
\hline Escritórios & Estágio I & Estágio II & Estágio III & Estágio IV \\
\hline Com até 25\% dos funcionários técnicos em contabilidade & 0,161 & 0,313 & 0,250 & 0,277 \\
\hline Entre 26\% a 50\% dos funcionários técnicos em contabilidade & 0,330 & 0,333 & 0,226 & 0,111 \\
\hline Entre 51\% a 75\% dos funcionários técnicos em contabilidade & 0,372 & 0,290 & 0,203 & 0,134 \\
\hline Entre 76\% a 100\% dos funcionários técnicos em contabilidade & 0,336 & 0,299 & 0,254 & 0,111 \\
\hline Utiliza pouco a intuição na tomada de decisão & 0,294 & 0,301 & 0,242 & 0,163 \\
\hline Utiliza muito a intuição na tomada de decisão & 0,343 & 0,334 & 0,222 & 0,101 \\
\hline Utiliza pouco a opinião dos clientes na tomada de decisão & 0,344 & 0,277 & 0,234 & 0,146 \\
\hline Não possui escrituração manual nas áreas adm. e financeira & 0,327 & 0,313 & 0,231 & 0,129 \\
\hline Não possui escrituração manual na área gerencial & 0,329 & 0,303 & 0,235 & 0,134 \\
\hline Utiliza pouco a pesquisa de mercado para TD* & 0,318 & 0,270 & 0,242 & 0,171 \\
\hline Utiliza pouco o banco de dados do escritório para TD & 0,335 & 0,301 & 0,253 & 0,110 \\
\hline Utiliza muito o sistema de informação gerencial para TD & 0,272 & 0,302 & 0,220 & 0,206 \\
\hline Utiliza pouco, planilhas elaboradas no Excel para TD & 0,327 & 0,298 & 0,241 & 0,134 \\
\hline Utiliza muito, planilhas elaboradas no Excel para TD & 0,324 & 0,355 & 0,215 & 0,107 \\
\hline Elabora o fluxo de caixa diariamente & 0,278 & 0,338 & 0,221 & 0,164 \\
\hline TD signifa toma
\end{tabular}

*TD significa tomada de decisão

Determinadas considerações podem ser expostas sobre os resultados anteriores. A 
princípio argumenta-se que o fato de se ter variáveis que possam ser estatisticamente significantes para explicar o nível de integração dos escritórios de contabilidade não influencia no estágio de integração. Isso porque, a proporção de empresas ao longo das fases é muito parecida, mesmo que os efeitos das variáveis sobre o sistema integrado sejam positivos ou negativos. As exceções são as variáveis "quantidade de técnicos em contabilidade", que tende a aumentar a proporção à medida que se passa do estágio II para o III, e "sistema de informação gerencial", que quando muito utilizada pelos escritórios, tem a segunda maior proporção de empresas no estágio IV.

Tabela 6- Estágios nos quais os escritórios de contabilidade estão de acordo com as variáveis estatisticamente significativas para explicar controle interno implantado

\begin{tabular}{|c|c|c|c|c|}
\hline & $\begin{array}{c}\text { Estágio } \\
\text { I }\end{array}$ & $\begin{array}{l}\text { Estágio } \\
\text { II }\end{array}$ & $\begin{array}{c}\text { Estágio } \\
\text { III }\end{array}$ & $\begin{array}{l}\text { Estágio } \\
\text { IV }\end{array}$ \\
\hline Escritórios com até $25 \%$ dos funcionários técnicos em contabilidade & 0,161 & 0,313 & 0,250 & 0,277 \\
\hline Escritórios entre $26 \%$ a $50 \%$ dos funcionários técnicos em contabilidade & 0,330 & 0,333 & 0,226 & 0,111 \\
\hline Escritórios entre $51 \%$ a $75 \%$ dos funcionários técnicos em contabilidade & 0,372 & 0,290 & 0,203 & 0,134 \\
\hline Escritórios entre $76 \%$ a $100 \%$ dos funcionários técnicos em contabilidade & 0,336 & 0,299 & 0,254 & 0,111 \\
\hline Escritórios que tem de 51 a 100 clientes & 0,336 & 0,316 & 0,236 & 0,112 \\
\hline Escritórios com até $25 \%$ dos clientes pertencentes ao segmento industrial & 0,332 & 0,310 & 0,231 & 0,127 \\
\hline $\begin{array}{l}\text { Escritórios em que } 26 \% \text { a } 50 \% \text { dos clientes pertencem ao segmento } \\
\text { industrial }\end{array}$ & 0,293 & 0,291 & 0,216 & 0,201 \\
\hline $\begin{array}{l}\text { Escritórios em que } 51 \% \text { a } 75 \% \text { dos clientes pertencem ao segmento } \\
\text { industrial }\end{array}$ & - & - & - & - \\
\hline $\begin{array}{l}\text { Escritórios em que } 76 \% \text { a } 100 \% \text { dos clientes pertencem ao segmento } \\
\text { industrial }\end{array}$ & - & - & - & - \\
\hline Os relatórios gerenciais são elaborados a partir do sistema informatizado & 0,331 & 0,315 & 0,229 & 0,124 \\
\hline Os relatórios gerenciais são elaborados a partir do sistema integrado & 0,253 & 0,281 & 0,249 & 0,217 \\
\hline Utiliza pouco as ações dos concorrentes para tomada de decisão & 0,271 & 0,285 & 0,229 & 0,215 \\
\hline Utiliza pouco as ideias dos clientes na tomada de decisão & 0,344 & 0,277 & 0,234 & 0,146 \\
\hline Utiliza muito as ideias dos clientes na tomada de decisão & 0,334 & 0,298 & 0,221 & 0,146 \\
\hline Elabora diariamente o orçamento & 0,406 & 0,156 & 0,156 & 0,281 \\
\hline Não possui escrituração manual nas áreas administrativa e financeira & 0,327 & 0,313 & 0,231 & 0,129 \\
\hline Não possui escrituração manual na área gerencial & 0,329 & 0,303 & 0,235 & 0,134 \\
\hline Utiliza pouco as opiniões dos funcionários na tomada de decisão & 0,321 & 0,293 & 0,258 & 0,129 \\
\hline Utiliza pouco relatórios integrados para tomada de decisão & 0,340 & 0,320 & 0,241 & 0,100 \\
\hline Utiliza muito relatórios integrados para tomada de decisão & 0,291 & 0,279 & 0,248 & 0,181 \\
\hline Utiliza pouco o sistema de informação gerencial para tomada de decisão & 0,373 & 0,280 & 0,254 & 0,094 \\
\hline Utiliza muito o sistema de informação gerencial para tomada de decisão & 0,272 & 0,302 & 0,220 & 0,206 \\
\hline Utiliza pouco consultas na internet para tomada de decisão & 0,319 & 0,290 & 0,244 & 0,147 \\
\hline Utiliza muito consultas na internet para tomada de decisão & 0,305 & 0,316 & 0,231 & 0,148 \\
\hline Elabora o demonstrativo de resultado mensalmente & 0,229 & 0,319 & 0,243 & 0,209 \\
\hline Elabora o demonstrativo de resultado trimestralmente & 0,322 & 0,278 & 0,242 & 0,158 \\
\hline Elabora o demonstrativo de resultado anualmente & 0,362 & 0,314 & 0,228 & 0,097 \\
\hline
\end{tabular}

Nota: - significa valor ausente

Com relação às variáveis que exercem efeitos positivos e negativos sobre o controle interno dos escritórios, observa-se que parece também não haver um relacionamento geral ou global entre as variáveis que são estatisticamente significativas para explicar o controle interno dos escritórios e os estágios nos quais eles estejam. Entretanto, existe questões que são importantes relatar. Por exemplo, escritórios que elaboram seus demonstrativos de resultado mensalmente, e possuem 
clientes em maior proporção no setor industrial, são os que, em maiores proporções, encontramse no estágio IV. Em contraposição, escritórios que utilizam pouco os relatórios integrados ou utilizam pouco o sistema de informação gerencial são os que, em menor proporção, encontram-se no estágio IV. Para finalizar esta seção, são apresentados os resultados obtidos para identificar os estágios dos escritórios a partir das variáveis de controle interno estatisticamente significativas. Logo em seguida apresentam-se as considerações finais, conclusões e recomendações para estudos futuros.

\section{CONSIDERAÇÕES FINAIS}

O objetivo deste estudo foi analisar o nível de gerenciamento e controle interno dos escritórios de contabilidade a partir da tipologia de quatro estágios desenvolvida por Kaplan e Cooper (1998) para projetar sistemas gerenciais. Foi possível identificar o nível de integração entre as áreas sobre os aspectos de qualidade de dados, emissão de relatórios e controles operacionais e estratégicos, constatando-se o grau de utilização de controle interno e sistemas integrados. Por fim, os escritórios foram classificados em um dos quatro estágios de gerenciamento desenvolvido de acordo com a abordagem do modelo de Kaplan e Cooper (1998).

Os dados foram coletados através de questionários respondidos pelos sócios contadores que atuam como administradores dos escritórios de contabilidade. Esses respondentes conheciam com profundidade todas as dimensões pesquisadas bem como as variáveis que estariam presentes no processo de gerenciamento. Assim, a partir de uma amostra de 112 escritórios pode-se observar que $32,84 \%$ desses escritórios estavam no estágio I, 30,55\% no estágio II, $23,35 \%$ no estágio III e $13,34 \%$ no estágio IV.

No estágio I, conforme pressupostos do modelo, os escritórios apresentam baixa confiabilidade na geração de relatórios financeiros e contábeis e têm como características algum tipo de escrituração que exige necessidade de tempo e recursos para consolidação das diferentes fontes de geração dos relatórios e para o fechamento dos livros ao final de cada período contábil. São comuns as variações inesperadas dos saldos contábeis ao final de cada período e muitos lançamentos de ajustes. Não existe controle dos clientes nem quanto às receitas e nem quanto às despesas individualizadas, nem é feito controle operacional e estratégico.

No estágio II, os escritórios suprem as exigências da geração de relatórios financeiros, porém não existe frequência; apresentam contas de resultados sintéticas com saldos distorcidos; não apresentam controle com receitas, custos ou despesas com clientes e possuem feedback limitado, sem tempo hábil para a tomada de decisão. Os controles gerenciais apresentados são desatualizados e limitados.

No estágio III, os escritórios utilizam sistemas informatizados para a geração dos relatórios financeiros e contábeis e controle operacional. Geralmente, utilizam sistemas que executam as funções contábeis, preparam as demonstrações financeiras mensais ou trimestrais e utilizam métodos convencionais de alocação de custos e despesas. Avaliam com maior precisão os custos de atividades, serviços, clientes; possuem algum tipo de controle operacional e estratégico, porém não utilizam com frequência.

Já estágio IV, no qual, detectaram-se apenas 13,34\% dos escritórios, indica a utilização de sistemas de informações integrados para a elaboração de todos os relatórios financeiros e 
contábeis que são utilizados para a tomada de decisão. É definido também como a integração do gerenciamento dos relatórios financeiros, o estágio mais avançado, e com informações geradas com confiabilidade e em curto espaço de tempo, que prepara demonstrações periódicas a partir de sistemas gerenciais; apresenta integração de dados com todas as áreas organizacionais, inclusive com os clientes do escritório; os relatórios são emitidos com frequência; as informações dos sistemas são utilizadas para o controle operacional e estratégico fundamentando a tomada de decisão.

Os resultados obtidos também sugerem menor preocupação de alguns escritórios de contabilidade com os controles internos tanto nas áreas gerenciadas pelos sócios proprietários, quanto nas áreas ligadas diretamente ao serviço prestado. Cabe observar que, esse tipo de organização tende a gerenciar melhor os seus processos e, com isso, a obter maior confiabilidade nas informações, geradas pelos sistemas informatizados, quando possuem controle interno implantado. Além disso, a utilização de sistemas integrados entre as áreas do escritório contribui para a diminuição do retrabalho, aumenta a possibilidade de gerenciamento das informações em curto prazo e fornece relatórios variados para servir de suporte na tomada de decisão.

Finalmente, entende-se que o gerenciamento dos escritórios de contabilidade contribui para a melhoria dos serviços prestados e o aumento da qualidade e da confiabilidade das informações fornecidas através da geração e do envio dos relatórios financeiros, contábeis e gerenciais para seus diversos tipos de usuários. Este estudo deixa espaço para novas pesquisas e esclarecimentos sobre o tema, apesar de algumas limitações como: os escritórios pertencerem somente à região de Belo Horizonte/MG; a dificuldade em validar o modelo de quatro estágios de Kaplan e Cooper nos escritórios que possuem poucas informações sobre os controles internos e a dificuldade de identificar como funciona o processo de tomada de decisão dos sócios contadores e gestores, devido ao pequeno porte desse tipo de empresa. Portanto, sugerem-se investigações que, procurem identificar em qual dos quatro estágios de gerenciamento se encontram outros escritórios de contabilidade existentes no Brasil e a aplicação do modelo de quatro estágios para acompanhar a migração de um estágio para o outro.

\section{REFERÊNCIAS}

ALBERTON, L.; LIMONGI, B.; KRUGER, N. Os reflexos da implementação de ERP em um escritório de contabilidade. In: CONGRESSO USP, 4., 2004, SP. Anais... São Paulo: USP, 2004.

ANTHONY, R. Contabilidade gerencial: uma introdução à contabilidade. São Paulo: Atlas, 1976.

ARAÚJO, C. A. S.; FIGUEIREDO, K. F. Gerenciamento da qualidade para o cliente interno: um estudo entre médicos de cinco hospitais brasileiros. In: ENANPAD, 30., 2006, Salvador. Anais... Rio de Janeiro: ANPAD, 2006.

BORDIN, P. B.; SARAIVA, C. J. S. O Controle interno como ferramenta fundamental para fidedignidade das informações contábeis. Revista Eletrônica de Contabilidade Universidade Federal de Santa Maria. Edição Especial. Julho/2005.

BRITO, L.; DUARTE, A.; DI SERIO, L. C. Práticas operacionais e o desempenho: uma análise empírica de empresas paulistas. In: ENANPAD, 31., 2007, Rio de Janeiro. Anais... Rio de Janeiro: ANPAD, 2007.

BRODBECK, Â. F.; TONOLLI, E.; COSTA, C. A. Orientação do alinhamento estratégico entre negócio e tecnologia de informação: uma análise focada no processo de desenvolvimento de 
produtos. In: ENANPAD, 32., 2008, Rio de Janeiro. Anais... Rio de Janeiro: ANPAD, 2008.

BRODBECK, Â. F.; RIGONI, E. H.; CANEPA, P. C. V. Uma análise do nível de maturidade do alinhamento estratégico entre negócio e tecnologia de informação. In: ENANPAD, 31., 2007, Rio de Janeiro. Anais... Rio de Janeiro: ANPAD, 2007.

DAVIS, R. C. Industrial organization and management. New York : Harper, 1940.

The Fundamentals of top management. New York: Harper, 1951.

The principles of factory organization and management. New York : Harper, 1928.

DENT, A. G. H. Budgetary control study. Industry illustred. Londres, v 2, may, 1934

GLOVER, J.G., MAZE, C.L. Managerial control. New York: Ronlad, 1937.

GRAEML, Alexandre Reis; MACIEL, Helton Francisco; MACADAR, Marie Anne. Análise de citações utilizadas em ADI: 10 anos de anais digitais do Enanpad (1997-2006). In: ENANPAD, 31., 2007, Rio de Janeiro. Anais... Rio de Janeiro: ANPAD, 2007.

GRAEML, A. R.; MACADAR, M. A; FILHO, E. R. Guarido; ROSSONI, Luciano. Redes Sociais e Intelectuais em ADI: Uma análise cientométrica do período 1997-2006 In: ENANPAD, 32., 2008, Rio de Janeiro. Anais... Rio de Janeiro: ANPAD, 2008.

.Uma análise cientométrica do período 1997-2006. In: ENANPAD, 32., 2008, Rio de Janeiro. Anais... Rio de Janeiro: ANPAD, 2008.

GOETZ, B.E.: Management planning and control. New York: McGraw-Hill, 1949.

HOLDEN, P. E., FISH, L. S., SMITH, H. I. Top management organization and control. Stanford university press, 1941.

HORNGREN, C.; FOSTER, G.; SRIKANT D. Contabilidade de custos. RJ: Editora LTC, 1997.

JOIA, L. A; MAGALHÃES, C. A. Evidências empíricas da resistência à implantação de prescrição eletrônica: Um Estudo de Caso. In: ENANPAD, 31., 2007, RJ. Anais... Rio de Janeiro: ANPAD, 2007.

LUNKES, R. J.; BRINCKMANN, R.; SCHNORRENBERGER, D.; GASPARETTO, V. Controladoria: um estudo bibliométrico no Congresso Brasileiro de Contabilidade de 2000, 2004 e 2008. Revista Brasileira de Contabilidade, n. 175, jan./fev. 2009.

KAPLAN, R. S. The Four-stage Model of cost System Design. Management Accounting, p. 22-26, feb. 1990.

.; COOPER, R. Custo e desempenho: administre seus custos para ser mais competitivo. São Paulo: Futura, 1998.

MARTIN, N. C. Da contabilidade à controladoria: a evolução necessária. Revista de Contabilidade \& Finanças, São Paulo, n. 28, p. 7-28, jan./abr. 2002.

MERCHANT, K. Modern management control systems: text \& cases. NJ: Prentice-Hall, 1997.

MOSIMANN, C. P.; FISCH, S. Controladoria: seu papel na administração de empresas. 2. ed. São Paulo: Atlas, 1999.

OLIVEIRA, Djalma de Pinho Rebouças. Sistemas de informações gerenciais: estratégias, táticas, operacionais. 8. ed. São Paulo: Atlas, 2002. 285 p.

OLIVEIRA, R. Contabilidade, controle Interno e controle externo: trinômio necessário para combater a corrupção. In: CONVENÇÃO DOS CONTABILISTAS DO ESTADO DO RJ, 49., 2004, Rio de Janeiro. Anais... Rio de Janeiro: CONCERJ, 2004.

PADOVEZE, C. L. Contabilidade Gerencial: um enfoque em sistema de informação contábil. 
4. ed. São Paulo: Atlas, 2004.

.Estruturação do sistema de informação contábil no ERP. In: ENANPAD, 24., 2004, Florianópolis. Anais... Rio de Janeiro: ANPAD, 2004.

PASSOS, F. U.; CEITA, K. de O. Avaliação de Práticas de implementação de projetos de sistemas de tecnologia da informação: survey em empresas de Salvador. In: ENANPAD, 32., 2008, Rio de Janeiro. Anais... Rio de Janeiro: ANPAD, 2008.

PEREIRA, A. N. A importância do controle interno para a gestão das empresas. In: CONGRESSO USP-INICIAÇÃO CIENTÍFICA EM CONTABILIDADE, 1., 2004, São Paulo. Anais... São Paulo: USP, 2004.

PRADO, E. P.; TAKAOKA, P. Terceirização de serviços de TI: um modelo para avaliação de relações de causa e efeito. In: ENANPAD, 31., 2007, Rio de Janeiro. Anais... RJ: ANPAD, 2007.

REZENDE, D. A. Planejamento de sistema de informação e informática: guia prático para planejar a tecnologia da informação integrada ao planejamento estratégico das organizações. São Paulo: Atlas, 2003. 185 p.

RODRIGUES, L. N. O sistema integrado de controle interno sob a ótica do artigo 74 da Constituição Federal: uma breve discussão teórica. Revista Brasileira de Contabilidade, n. 174, nov./dez. 2008.

ROWLAND, D. W. History of the office of the coordinator of inter-american affairs: historical report on war administration. Whashington: Government Printing Office, 1947.

SABBADINI, F. S.; OLIVEIRA, M. J. F. Gerenciamento de restrições na identificação e solução de problemas em emergência hospitalar: Uma Abordagem Orientada ao Paciente. In: ENANPAD, 31., 2007, Rio de Janeiro. Anais... Rio de Janeiro: ANPAD, 2007.

SILVA, F. F da. Sistemas de gerenciamento de custos e desempenho aplicando o modelo de Kaplan e Cooper em grandes industrias de transformação do estado de Pernambuco. 2003. Dissertação (Mestrado em Engenharia de Produção) - Programa de Pós-Graduação em Engenharia de Produção, UFPE, Recife, 2003.

SILVA, C. A. T.; LIMA, D. H. S. Formulation Effect: Influência da forma de apresentação sobre o processo decisório de usuários de informações financeiras. In: ENANPAD, 31., 2007, Rio de Janeiro. Anais... Rio de Janeiro: ANPAD, 2007.

SORDIDE, J. O. de; COSTA, M. A. M. da; GRIJÓ, R. N. Gestão de qualidade da informação no contexto das organizações: percepções a partir do experimento de análise da confiabilidade dos jornais eletrônicos. In: ENANPAD, 32., 2008, Rio de Janeiro. Anais... RJ: ANPAD, 2008.

SPELTA, A. G.; ALBERTIN, A. L. A. Um Modelo Conceitual da Decisão de Criação de Escritório de Projetos na Área de TI. In: ENANPAD, 32., 2008, RJ. Anais... RJ: ANPAD, 2008.

THEODORO, A. J. O suporte informacional da controladoria na gestão das empresas centenárias do Rio Grande do Sul. Dissertação (Mestrado em Ciências Contábeis) - Programa de Pós-Graduação em Ciências Contábeis, Universidade Regional de Blumenau, SC, 2006.

VELLANI, C. L.; RIBEIRO, S. M. Sistema contábil para gestão da ecoeficiência empresarial. Revista Contabilidade \& Finanças, São Paulo, n. 20, p. 25-43, jan./abr. 2009.

YOUNG, N. R. Auditoria interna: herramienta vital para el éxito. In: CONFERENCIA INTERAMERICANA DE CONTABILIDADE, 28., 2009, Cancun. Anais... Mexico: Conferencia Interamericana de Contabilidade, 2009.

WARREN, Carl S.; REVÉ, James M.; FESS, Philip E. Contabilidade Gerencial.São Paulo. Pioneira Thomson Learning, 2001. 
Sistema de Gerenciamento e Controle Interno: uma Análise dos Escritórios de Contabilidade de Belo Horizonte/MG e Região Metropolitana a partir da Taxonomia de Kaplan e Cooper

\section{ENDEREÇO DOS AUTORES:}

\section{Wendel Alex Castro Silva}

Faculdade Novos Horizontes.

Rua Alvarega Peixoto, 1270 - Santo Augustinho

Belo Horizonte, MG - Brasil

30180-121

\section{Adriana Maria Rocha}

Faculdade Novos Horizontes

Rua Nascimento 101

Araguaia

Belo Horizonte, MG - Brasil

30620-390

\section{Alfredo Alves Oliveira Melo}

Faculdade Novos Horizontes.

Rua Alvarega Peixoto, 1270 - Santo Augustinho

Belo Horizonte, MG - Brasil

30180-121 